\title{
Is coronene better described by Clar's aromatic $\pi$-sextet model or by the AdNDP representation?
}

\author{
Anand Kumar, ${ }^{1,2}$ Miquel Duran ${ }^{2}$ and Miquel Solà ${ }^{2 *}$ \\ ${ }^{1}$ Department of Chemistry, Indian Institute of Science Education and Research, Pune, Dr. Homi \\ Bhabha Road, Pune, 411008, Maharashtra, India. \\ ${ }^{2}$ Institut de Química Computacional i Catàlisi (IQCC) and Department de Química, Universitat de \\ Girona, c/ Maria Aurèlia Capmany 6, 17003 Girona, Catalonia, Spain. E-mail: miquel.sola@udg.edu
}

\begin{abstract}
The bonding patterns in coronene are complicated and controversial as denoted by the lack of consensus of how its electronic structure should be described. Among the different proposed descriptions, the two most representative are those generated by Clar's aromatic $\pi$-sextet and Adaptative Natural Density Partitioning (AdNDP) models. Quantum-chemical calculations at the density functional theory level are performed to evaluate the model that gives a better representation of coronene. To this end, we analyse the molecular structure of coronene, we estimate the aromaticity of its inner and outer rings using various local aromaticity descriptors, and we assess its chemical reactivity from the study of the Diels-Alder reaction with cyclopentadiene. Results obtained are compared with those computed for naphthalene and phenanthrene. Our conclusion is that Clar's $\pi$ sextet model provides the representation of coronene that better describes the physicochemical behaviour of this molecule.
\end{abstract}

Keywords: Clar's aromatic $\pi$-sextet; Adaptative Natural Density Partitioning; Harmonic oscillator model of aromaticity; para-delocalization index; aromatic fluctuation index; nucleus independent chemical shift; Diels-Alder.

\footnotetext{
* This work is dedicated to Prof. Dr. Eluvathingal D. Jemmis on his $65^{\text {th }}$ birthday for his pioneering contributions to chemistry.
} 


\section{Introduction}

Aromaticity is one of the most distinguished concepts in physical organic chemistry. It is crucial for understanding the geometry, stability, spectroscopy, and chemical reactivity of a considerable number of molecules. ${ }^{[1-6]}$ In 1931, Hückel laid the stepping stone by proposing the acclaimed Hückel's $4 n+2$ rule to identify aromaticity in annulenes. ${ }^{[7-10]}$ Since the applications of Hückel's $4 n+2$ rule were limited to monocyclic conjugated systems, several trials were performed to generalize this rule to polycyclic systems. Amidst them, one of the most prominent model was Clar's aromatic $\pi$-sextet rule, ${ }^{[11-12]}$ which claims that the Kekule structure with the largest number of disjoint aromatic $\pi$-sextets, i.e. the so-called Clar valence structure, is the one that offers the best description of benzenoid polycyclic aromatic hydrocarbons (PAHs). This model was extended by Glidewell and Lloyd ${ }^{[13]}$ to polycyclic conjugated hydrocarbons having rings with any even number of carbon atoms in their structure. ${ }^{[14]}$ Several studies among the years provided support to

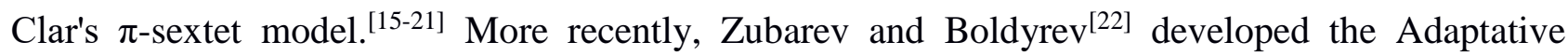
Natural Density Partitioning (AdNDP) method as an improvement of the Natural Bond Orbital $(\mathrm{NBO})^{[23-24]}$ analysis. In the AdNDP approach, the charge density is partitioned into n-center 2electron bonds (nc-2e) with the highest possible degree of localization of electron pairs. In this manner, AdNDP recovers both Lewis bonding elements (1c-2e and 2c-2e objects, corresponding to the core electrons and lone pairs, and 2c-2e bonds) and delocalized bonding elements, which are associated with the concepts of multicenter bonding and aromaticity. AdNDP is a very efficient and visual method to analyse molecular orbital-based wave functions. This method has successfully described the chemical bonding patterns in several molecular clusters with many delocalized bonds providing interesting information and deep insight. ${ }^{[25-29]}$ Interestingly, for PAHs that can be described with a unique Clar valence structure (for instance, phenanthrene, triphenylene, or circumcoronene), the description of the chemical bonding given by Clar's $\pi$-sextet model and the AdNDP approach coincide. ${ }^{[30-31]}$ On the contrary, for PAHs described by a combination of several Clar valence structures (for instance, naphthalene, anthracene, or coronene), the two representations disagree. The discrepancy is attributed to the fact that the AdNDP analysis looks for the most compact single structure that can be used to define chemical bonding in a certain compound whereas Clar's $\pi$-sextet model uses a resonant description of the chemical bond. ${ }^{[30]}$

Hexabenzobenzene or coronene $\left(\mathrm{C}_{24} \mathrm{H}_{12}\right)$ is one of the PAHs in which the chemical bonding pattern described by Clar and AdNDP models ${ }^{[31]}$ differ. This benzenoid PAH with applications in materials chemistry, ${ }^{[32-35]}$ comprises six benzene rings annelated to a benzene core and represents a basic graphene fragment. It is found naturally as a mineral called carpathite and is produced in hydrocracking petroleum-refining process. ${ }^{[36]}$ Although initially it was considered coronene as a 
superaromatic compound, ${ }^{[37]}$ it is now widely accepted that it is not. ${ }^{[19,38-46]}$ In fact, the aromatic stabilization energy (ASE) of coronene per $\pi$-electron was found to be significantly lower than that of pyrene that, in turn, is much lower than that of benzene. ${ }^{[45-46]}$ Coronene structure can be represented by 20 covalent resonance structures, two of them having three $\pi$-sextets and $D_{3 h}$ symmetry (structures 1 and 2 in Scheme 1). The Clar valence structure, which is a combination of the two $D_{3 h}$ resonant structures with three $\pi$-sextets, has $\mathrm{D}_{6 \mathrm{~h}}$ symmetry with three $\pi$-sextets that can migrate into the adjacent rings (structure I, Scheme 1). Therefore, one can consider that each outer ring of coronene has half a $\pi$-sextet, whereas no $\pi$-sextet is located in the inner 'empty ring'. On the other hand, according to the AdNDP model, ${ }^{[30-31]}$ the 108 valence electrons of coronene are distributed in $302 \mathrm{c}$ 2e C- $\mathrm{C} \sigma$ bonds, 12 2c-2e C-H bonds, six $2 \mathrm{c}-2 \mathrm{e} \pi$ bonds, three $6 \mathrm{c}-2 \mathrm{e} \pi$ bonds, and three $24 \mathrm{c}-2 \mathrm{e} \pi$ bonds (structure II, Scheme 1). In the AdNDP representation, the $\pi$-system coronene is reminiscent to that of the $\mathrm{B}_{19}{ }^{-}$species, ${ }^{[47]}$ an aromatic Wankel motor ${ }^{[48]}$ with double $\pi$-aromaticity in two concentric $\pi$-systems.

\section{SCHEME 1, here}

The estimated local properties of coronene differ considerably depending on which representation one considers. For instance, bond $\mathrm{C} 1-\mathrm{C} 2$ should be in between intermediate and double bond somewhat closer to double bond in Clar's representation, whereas it should have slightly more than double bond character in the AdNDP model. Similarly, the aromaticity of the outer ring A (Scheme 1) should be larger than that of the inner ring $\mathbf{B}$ in the Clar model and the other way round according to the AdNDP representation. In the present work, we investigate the best-suited model between Clar's aromatic $\pi$-sextet and AdNDP forms for representing coronene. To this end, we have analysed the molecular structure, aromaticity, and reactivity of coronene as compared to that of naphthalene and phenanthrene. We agree with Kutzelnigg who said:[49] "Understanding without models is impossible. However, a model is useful, only if one understands its scope and limitations." In this sense, we think it is worth to look for possible shortages of these models keeping in mind that models are just intrinsically deficient approximations to reality and that there is no perfect model. However, when comparing different models the degree of approximation to reality can be different and it is relevant to know which is the model that better approaches it and, consequently, is more useful. As Dewar wrote:[50] "the only criterion of a model is usefulness, not its "truth"”.

\section{Computational Details}

All considered geometries were optimized using hybrid density functional theory (DFT) with the M06-2X ${ }^{[51]}$ and B3LYP ${ }^{[52-54]}$ methods in conjunction with the cc-pVTZ Dunning type basis set. ${ }^{[55]}$ 
Grimme's-D3 dispersion correction ${ }^{[56]}$ with the Becke-Johnson (BJ) damping ${ }^{[57-59]}$ was included in all B3LYP calculations. These two functionals perform quite well for the predicting relative energies of polycyclic aromatic hydrocarbons. ${ }^{[60]}$ Harmonic vibrational frequencies were performed to characterize the nature of stationary points and to obtain enthalpies and Gibbs energies. The reported minima and transition states structures exhibited zero and one imaginary frequencies, respectively. All geometry optimizations and frequency calculations were carried out using the Gaussian 09 set of programs. ${ }^{[61]}$ Following previous recommendations, ${ }^{[62-64]}$ the local aromaticity in the systems considered was studied using several aromaticity indices like the geometric-based ${ }^{[65-66]}$ harmonic model of aromaticity (HOMA), ${ }^{[67-68]}$ the electronic-based ${ }^{[69-70]}$ para-delocalization index (PDI), ${ }^{[71]}$ aromatic fluctuation index (FLU), ${ }^{[72]}$ Giambiagi's index $\left(\mathrm{I}_{\text {ring }}\right),{ }^{[73]}$ and multicentre index (MCI), ${ }^{[43]}$ and the magnetic-based ${ }^{[74-77]}$ nucleus-independent chemical shift (NICS). ${ }^{[78-79]}$ The NICS was evaluated using the regular GIAO method ${ }^{[80]}$ on probing ghost atoms at the ring centres and to $1.0 \AA$ away from the ring centre following the perpendicular of the molecular plane. We also performed NICS- $X Y$-scans. ${ }^{[77,81]}$ These scans can distinguish the global (current along the perimeter of whole molecule) and local (current inside each circuit) currents in $\pi$-conjugated polycyclics. The NICS- $X Y$ scans were recorded using NICS $_{\text {zz }}$ values at $1.7 \AA$ above the molecular plane at the M06-2X/cc-pVTZ computational level. As to the aromaticity indices calculated, the aromaticity of a given ring increases when HOMA, PDI, Iring, and MCI increase and FLU and NICS decrease. All electronic indices of aromaticity were obtained with the ESI-3D program ${ }^{[72,82]}$ using overlaps of molecular orbitals generated by the AIMALL program ${ }^{[83]}$ and calculated with the Atoms-in-Molecules atomic partition. ${ }^{[84-85]}$

\section{Results and Discussion}

Scheme 2 illustrates the Clar and AdNDP representations of naphthalene and phenanthrene and the Clar model of pyrene. The latter PAH has a unique Clar valence structure and, therefore, it is likely that AdNDP provides the same description as the Clar model. Naphthalene, phenanthrene, and pyrene can be considered fragments of coronene with different bonding patterns. We will compare the molecular structure, aromaticity, and reactivity of these fragments with those of coronene to discuss whether coronene is better described by Clar or AdNDP representations. We will focus our comparisons on naphthalene and phenanthrene. The results of pyrene, having a similar bonding pattern as phenanthrene are given in the Supporting Information (SI).

This section is organized as follows. First, we discuss the molecular structure of coronene, second, we analyse the local aromaticity of the inner and outer ring of coronene, and, finally, we study the reactivity of coronene in Diels-Alder reactions. 


\section{SCHEME 2, here}

\section{a. The molecular structure of coronene.}

Root-mean-square deviations (RMSDs) ${ }^{[86]}$ of theoretical bond lengths for the two distinct DFT levels with respect to experimental values of Scheme 3 indicate similar accuracy for the M062X/cc-pVTZ (RMSD = $0.060 \AA$ ) and B3LYP/cc-pVTZ (RMSD $=0.062 \AA$ ) levels of theory (Table $\mathrm{S} 1$ collects the RMSDs for fourteen different functionals with values ranging from $0.060 \AA$ for M062X to $0.084 \AA$ for $S V W N)$. We have decided to focus our comments on the M06-2X/cc-pVTZ results and move the B3LYP/cc-pVTZ results to the SI. The conclusions extracted from the B3LYP/ccpVTZ results are the same as those derived from the M06-2X/cc-pVTZ calculations. Scheme 3 gives the bond lengths of naphthalene, phenanthrene, pyrene, and coronene. According to the AdDNP representation, the short outer $\mathrm{C} 1-\mathrm{C} 2$ bond (Scheme 1) in coronene has a bond order of $2.1(2 \mathrm{c}-2 \mathrm{e} \sigma$ bond, $2 \mathrm{c}-2 \mathrm{e} \pi$ bond, and three $24 \mathrm{c}-2 \mathrm{e} \pi$ bonds; for these latter we consider the three electron pairs equally distributed among the 30 bonds of coronene). On the contrary, the Clar description considers that the bond order of the $\mathrm{C} 1-\mathrm{C} 2$ bond in coronene is 1.75 . Scheme 3 shows that the $\mathrm{C} 9-\mathrm{C} 10$ double bond in phenanthrene $\left(1.348 \AA\right.$, exp. $\left.1.341 \AA^{[87]}\right)$ has a shorter bond length than the $\mathrm{C} 1-\mathrm{C} 2$ bond of coronene (1.362 $\AA$, exp. $\left.1.357 \AA^{[88]}\right)$. Clar's description conforms better this experimental observation. Moreover, the long outer $\mathrm{C} 2-\mathrm{C} 2 \mathrm{a}$ bond in coronene should have a bond order of 1.1 and 1.25 according to the AdNDP and Clar models. Similarly, the bond order of the central $\mathrm{C} 2 \mathrm{a}^{1}-\mathrm{C} 4 \mathrm{a}^{1}$ bond in coronene is 1.6 and 1.25 in the AdNPD and Clar representations, respectively. And the spoke $\mathrm{C} 2 \mathrm{a}^{1}-\mathrm{C} 2 \mathrm{a}$ predicted bond orders are 1.1 and 1.5 in the AdNDP and Clar description. Therefore, AdNDP predicts the central $\mathrm{C} 2 \mathrm{a}^{1}-\mathrm{C} 4 \mathrm{a}^{1}$ bond $(1.421 \AA$, exp. $1.424 \AA$ ) to be shorter that the spoke $\mathrm{C} 2 \mathrm{a}^{1}-\mathrm{C} 2 \mathrm{a}$ bond (1.408 $\AA$, exp. $1.416 \AA$ ), whereas Clar's model indicates the contrary. Experimental values favour the expectation of Clar's model. In addition, Clar's model predicts similar bond lengths for the long outer C2-C2a bond (1.419 $\AA$, exp. $1.420 \AA$ ) and the central C2a $\mathrm{a}^{1}-\mathrm{C} 4 \mathrm{a}^{1}$ bond $(1.421 \AA$, exp. $1.424 \AA$ ) as found experimentally, whereas AdNDP indicates shorter central than outer bond length. Finally, the fact that the spoke $\mathrm{C} 2 \mathrm{a}^{1}-\mathrm{C} 2 \mathrm{a}$ bond of coronene $(1.408 \AA$, exp. $1.416 \AA$ ) is closer to the $\mathrm{C} 4-\mathrm{C} 4 \mathrm{a}$ of naphthalene (1.415 $\AA$, exp. $1.425 \AA$ ) than to the $\mathrm{C} 8 \mathrm{a}-\mathrm{C} 9$ of phenanthrene $(1.434 \AA$, exp. $1.450 \AA$ ) supports the conclusion that, geometrically, the outer rings of coronene are more similar to the rings of naphthalene than to the central ring of phenanthrene, thus favouring Clar's representation. 


\section{b. The local aromaticity of coronene.}

In the AdNDP model, the inner ring of coronene is expected to be more aromatic than outer ring. On the contrary, Clar's $\pi$-sextet scheme suggests the local aromaticity of the outer ring to be larger than that of the inner ring. Table 1 collects FLU, PDI, MCI, Iring, NICS $(1)_{\mathrm{zz}}$, and HOMA values of the investigated PAHs. All indices agree indicating that the outer ring $\mathbf{A}$ is more aromatic than the inner ring B. HOMA is the index showing the smallest difference between the two rings. In addition, HOMA is the only index that considers ring $\mathbf{B}$ of coronene more aromatic than that of phenanthrene. These results seems to indicate that HOMA overestimates the aromaticity of ring $\mathbf{B}$ of coronene. On the other hand, NICS $(1)_{z z}$ is the indicator providing the largest dissimilarity between rings $\mathbf{A}$ and $\mathbf{B}$ of coronene. As it is well-known, in fused polycyclic conjugated hydrocarbons, NICS measure is affected by the couplings between induced magnetic fields generated by adjacent rings. ${ }^{[89-93]}$ In fact, it has been already suggested that the NICS value of the inner ring of coronene is underestimated and it should be more negative. ${ }^{19,88}$ We also calculated the NICS-X-scan for the different species (see Fig. 1 for coronene and Fig. S2 for the rest of species studied). Results of the NICS-X-scan also points out that the outer ring is the most aromatic in coronene. Not only the indices used in this work, but also other indices used in previous works like NICS $(0),{ }^{[31,42,44,94]} \operatorname{NICS}(1),{ }^{[16,19,31,42,44]} \mathrm{NICS}(0)_{\mathrm{zz}},{ }^{[31]}$ $\operatorname{NICS}(0)_{\pi z z},{ }^{[95]}$ SSE, ${ }^{[19]}$ BOIA, ${ }^{[19,43]}$ and $\mathrm{ATI}^{[43]}$ as well as FLU, PDI, and MCI calculated with the Hückel molecular orbital method ${ }^{[96]}$ point in the same direction. In addition, the topography of the molecular electrostatic potential of coronene ${ }^{[97-98]}$ strongly support the Clar's model that describes the innermost ring of coronene as an 'empty ring'. The only index that gives a large aromaticity for the central ring is the extra cyclic resonance energy (ECRE) that indicates the inner ring of coronene to have similar aromaticity than benzene. ${ }^{[95]}$ In summary, the outer ring of coronene is more aromatic than the inner ring and this result is in accordance with Clar's model prediction. This conclusion agrees with scanning tunnelling microscope (STM) images that show coronene as a hollow ring like structure with a circular protrusion for the outer rings of coronene and a small depression for the central 'empty ring'. ${ }^{[99-100]}$ Finally, all indices in Table 1 except NICS $(1)_{\mathrm{zz}}$, consider that the aromaticity of the outer ring of coronene is closer to that of the ring of naphthalene than to that of the outer ring of phenanthrene and that the aromaticity of the inner ring in coronene is similar (but somewhat lower except in the case of HOMA) to that of the central ring in phenanthrene.

\section{TABLE 1 and FIGURE 1, here}

The ring currents of coronene were computed in previous works using different approximations. ${ }^{[19,39-41,44,76,101-102]}$ These studies showed the presence of a diamagnetic ring current 
in the [18]annulene periphery and a weak paramagnetic ring current in the central six-membered ring. This pattern of ring currents was interpreted as the result of a combination of diamagnetic local ring currents in all six-membered rings. ${ }^{[19,40-41]}$ This combination also explains the lack of radial currents. Moreover, considering the intensity of the outer rings being two or three times stronger than that of the inner ring, the observed global pattern of counter-rotating strong rim and weak hub currents in coronene is perfectly reproduced. ${ }^{[19,40-41]}$ A more intense diamagnetic local ring current in the outer rings concurs with the larger aromaticity attributed to these rings as compared to the inner ring by all indices of aromaticity. This picture of local ring currents is analogous to that derived from the Clar's model. In the AdNDP representation, we have a $6 \pi($ i.e, $4 n+2)$ inner circuit with three $6 \mathrm{c}-2 \mathrm{e} \pi$ bonds and another $6 \pi$ circuit in the periphery with three $24 \mathrm{c}-2 \mathrm{e} \pi$ bonds. Since the two circuits have $6 \pi$ electrons, one should observe two (inner and outer) diamagnetic ring currents.

In summary, many descriptors of aromaticity points out that the outer rings of coronene are more aromatic than the central ring. In addition, the ring currents show a diamagnetic ring current in the [18]annulene rim and a weak paramagnetic ring current in the [6] annulene inner perimeter. These observations are more in line with expectations from Clar's model than from the AdNDP representation.

\section{c. The reactivity of coronene.}

In this last section, we study the Diels-Alder (DA) reaction between the analysed PAHs and cyclopentadiene. We calculated the endo and exo approaches for the DA, although in Table 2 we gather only the results for the thermochemistry and kinetics of the exo approach, which is the most favourable approach for most of the systems studied. However, the results of the endo approach are also provided in the SI. The DA reaction has been studied on the $\mathrm{C} 1-\mathrm{C} 2$ bond of coronene, the C9$\mathrm{C} 10$ bond of phenanthrene, and the $\mathrm{C} 1-\mathrm{C} 2$ bond of naphthalene. As before, we consider that the reactivity of the $\mathrm{C} 1-\mathrm{C} 2$ bond in coronene has to be more similar to that of $\mathrm{C} 9-\mathrm{C} 10$ bond in phenanthrene if the AdDNP representation is followed and to that of $\mathrm{C} 1-\mathrm{C} 2$ bond of naphthalene according to the Clar description.

\section{TABLE 2, here}

Values of Table 2 indicate that the most and least reactive bonds are those of phenanthrene and naphthalene, respectively. The reaction energy and energy barriers of the $\mathrm{C} 1-\mathrm{C} 2$ bond in coronene differ by less than $0.7 \mathrm{kcal} \mathrm{mol}^{-1}$ from those of the $\mathrm{C} 1-\mathrm{C} 2$ bond of naphthalene, whereas differences are larger than $2.5 \mathrm{kcal} \mathrm{mol}^{-1}$ when compared to those of the $\mathrm{C} 9-\mathrm{C} 10$ bond in 
phenanthrene. Hence, this reactivity analysis shows coronene being more 'naphthalene-like' than 'phenanthrene-like', thus emphasizing Clar's model as a prime representation of coronene. Finally, results in Table 2 clearly show that coronene cannot undergo Diels-Alder reactions in the C1-C2 bond because of the high barrier and endergonic nature of the reaction.

As a whole, analysis of the molecular structure, aromaticity, and reactivity indicates that the Clar representation of coronene describes better its bonding pattern than the AdNDP model. This view is also supported by ring currents calculations and STM images of coronene. We attribute the failure of AdNDP to provide a better representation of coronene to the fact that AdNDP by construction looks for the single most compact description avoiding a resonant description of the chemical bond. We argue that PAHs that are described in Clar's $\pi$-sextet model with Clar valence structures having $\pi$-migrating sextets, are not well-represented by a single structure. In fact, if threshold for acceptance of $2 \mathrm{c}-2 \mathrm{e}$ bonds in the AdNDP analysis is reduced to $1.55 \mathrm{e}$, the AdNDP method recovers a Kekulé structure like 1 in Scheme $1 .^{[30]}$ It is likely that if resonance were introduced in AdNDP analysis, the result would be a combination of structures $\mathbf{1}$ and $\mathbf{2}$ in Scheme 1, i.e., the same representation given by Clar's theory. Finally, although we consider that, for coronene, the representation given by Clar's method is better than that provided by the AdNDP approach, it is important to emphasize that Clar's model is restricted to benzenoid PAHs, whereas AdNDP can be applied to any chemical system.

\section{Conclusions}

The representation of the bonding pattern in coronene is complicated and controversial. In the present work, we compare the descriptions of this molecule given by Clar's $\pi$-sextet model and the Adaptative Natural Density Partitioning (AdNDP) method, the aim being to find the best representation of the bonding in coronene. To this end, we analyse the molecular structure, the local aromaticity, and the local chemical reactivity of coronene as a dienophile in a Diels-Alder reaction with cyclopentadiene. Keeping in mind that any model of the bonding pattern is intrinsically deficient as it makes approximations, the results obtained favour the Clar representation as the best suited to describe the chemical bond in coronene. We attribute the possible origin of the shortcoming of AdNDP when applied to coronene to the need of including resonant structures in the description of this molecule. 


\section{Acknowledgments}

The authors acknowledges the support of the Ministerio de Economía y Competitividad of Spain (Project CTQ2014-54306-P), Generalitat de Catalunya (project number 2014SGR931, Xarxa de Referència en Química Teòrica i Computacional, and ICREA Academia prize 2014 for MS), and European Fund for Regional Development (FEDER grant UNGI10-4E-801). AK thanks to Department of Science\&Technology, India for INSPIRE fellowship and Infosys Foundation for the financial support. MS is very grateful to Dr. A. A. Dyrda and her team for the surgery that allowed him to recover the vision of the right eye after retinal detachment. MS thanks his wife for post-operative care.

\section{Supporting information}

RMSD values for fourteen different functionals, thermochemical and kinetic data for endo and exo of the Diels-Alder with cyclopentadiene approaches for all systems studied, aromaticity indices for rings of pyrene, transition state figures, NICS-XY-scan for all studied systems, as well as Cartesian coordinates of all optimized geometries. This material is available free of charge via the Internet at ... 


\section{References}

[1] P. v. R. Schleyer, H. Jiao, Pure Appl. Chem. 1996, 68, 209-218.

[2] T. M. Krygowski, M. K. Cyrañski, Z. Czarnocki, G. Häfelinger, A. R. Katritzky, Tetrahedron 2000, 56, 1783-1796.

[3] P. v. R. Schleyer, Chem. Rev. 2001, 101, 1115-1118.

[4] P. v. R. Schleyer, Chem. Rev. 2005, 105, 3433-3435.

[5] N. Martin, L. T. Scott, Chem. Soc. Rev. 2015, 44, 6397-6400.

[6] G. Merino, M. Solà, Phys. Chem. Chem. Phys. 2016, 18, 11587-11588.

[7] E. Hückel, Z. Physik 1931, 70, 104-186.

[8] E. Hückel, Z. Physik 1931, 72, 310-337.

[9] E. Hückel, Z. Physik 1932, 76, 628-648.

[10] E. Hückel, Z. Elektrochemie 1937, 43, 752-788, 827-849.

[11] E. Clar, The Aromatic Sextet, Wiley, New York, 1972.

[12] M. Solà, Front. Chem. 2013, 1, 22.

[13] C. Glidewell, D. Lloyd, Tetrahedron 1984, 40, 4455-4472.

[14] O. El Bakouri, J. Poater, F. Feixas, M. Solà, Theor. Chem. Acc. 2016, 135, 205.

[15] R. Dabestani, I. N. Ivanov, Photochem. \& Photobiol. 1999, 70, 10-34.

[16] D. Moran, F. Stahl, H. F. Bettinger, H. F. Schaefer, P. v. R. Schleyer, J. Am. Chem. Soc. 2003, 125, 6746-6752.

[17] G. Portella, J. Poater, M. Solà, J. Phys. Org. Chem. 2005, 18, 785-791.

[18] E. Steiner, P. W. Fowler, A. Soncini, L. W. Jenneskens, Faraday Discuss. 2007, 135, 309323.

[19] J.-i. Aihara, M. Makino, K. Sakamoto, J. Phys. Chem. A 2013, 117, 10477-10488.

[20] A. Soncini, E. Steiner, P. W. Fowler, R. W. A. Havenith, L. W. Jenneskens, Chem. Eur. J. 2003, 9, 2974-2981.

[21] L. Gross, F. Mohn, N. Moll, B. Schuler, A. Criado, E. Guitián, D. Peña, A. Gourdon, G. Meyer, Science 2012, 337, 1326-1329.

[22] D. Y. Zubarev, A. I. Boldyrev, Phys. Chem. Chem. Phys. 2008, 10, 5207-5217.

[23] J. P. Foster, F. Weinhold, J. Am. Chem. Soc. 1980, 102, 7211-7218.

[24] A. E. Reed, L. A. Curtiss, F. Weinhold, Chem. Rev. 1988, 88, 899-926.

[25] A. P. Sergeeva, D. Y. Zubarev, H.-J. Zhai, A. I. Boldyrev, L.-S. Wang, J. Am. Chem. Soc. 2008, 130, 7244-7246.

[26] D. Y. Zubarev, A. I. Boldyrev, J. Phys. Chem. A 2009, 113, 866-868.

[27] J. M. Mercero, A. I. Boldyrev, G. Merino, J. M. Ugalde, Chem. Soc. Rev. 2015, 44, 65196534.

[28] A. P. Sergeeva, I. A. Popov, Z. A. Piazza, W.-L. Li, C. Romanescu, L.-S. Wang, A. I. Boldyrev, Acc. Chem. Res. 2014, 47, 1349-1358.

[29] A. P. Sergeeva, A. I. Boldyrev, Comm. Inorg. Chem. 2010, 31, 2-12.

[30] D. Y. Zubarev, A. I. Boldyrev, J. Org. Chem. 2008, 73, 9251-9258.

[31] I. A. Popov, A. I. Boldyrev, Eur. J. Org. Chem. 2012, 3485-3491.

[32] M. D. Watson, F. Jäckel, N. Severin, J. P. Rabe, K. Müllen, J. Am. Chem. Soc. 2004, 126, 1402-1407.

[33] S. Yoshimoto, E. Tsutsumi, O. Fujii, R. Narita, K. Itaya, Chem. Commun. 2005, 1188-1190.

[34] A. H. Endres, M. Schaffroth, F. Paulus, H. Reiss, H. Wadepohl, F. Rominger, R. Krämer, U. H. F. Bunz, J. Am. Chem. Soc. 2016, 138, 1792-1795.

[35] C. Chakravarty, B. Mandal, P. Sarkar, Phys. Chem. Chem. Phys. 2016, 18, 25277-25283.

[36] W. S. Kmak, A. Yatabe, US4222852 A, USA, 1980.

[37] E. Clar, Ü. Sanigök, M. Zander, Tetrahedron 1968, 24, 2817-2823.

[38] J.-i. Aihara, Bull. Chem. Soc. Jpn. 1993, 66, 57-60.

[39] E. Steiner, P. W. Fowler, L. W. Jenneskens, Angew. Chem. Int. Ed. 2001, 40, 362-266.

[40] A. Acocella, R. W. A. Havenith, E. Steiner, P. W. Fowler, L. W. Jenneskens, Chem. Phys. 
Lett. 2002, 363, 64-72.

[41] J.-i. Aihara, Chem. Phys. Lett. 2004, 393, 7-11.

[42] M. Güell, J. Poater, J. M. Luis, O. Mó, M. Yáñez, M. Solà, ChemPhysChem 2005, 6, 25522561.

[43] P. Bultinck, R. Ponec, S. Van Damme, J. Phys. Org. Chem. 2005, 18, 706-718.

[44] A. Ciesielski, M. K. Cyrański, T. M. Krygowski, P. W. Fowler, M. Lillington, J. Org. Chem. 2006, 71, 6840-6845.

[45] M. A. Dobrowolski, A. Ciesielski, M. K. Cyrański, Phys. Chem. Chem. Phys. 2011, 13, 20557-20563.

[46] A. Ciesielski, D. K. Stepien, M. A. Dobrowolski, L. Dobrzycki, M. K. Cyrański, Chem. Commun. 2012, 48, 10129-10131.

[47] W. Huang, A. P. Sergeeva, H.-J. Zhai, B. B. Averkiev, L.-S. Wang, A. I. Boldyrev, Nat. Chem. 2010, 2, 202-206.

[48] J. O. C. Jiménez-Halla, R. Islas, T. Heine, G. Merino, Angew. Chem. Int. Ed. 2010, 49, 56685671.

[49] W. Kutzelnigg, J. Comput. Chem. 2007, 28, 25-34.

[50] M. J. S. Dewar, J. Am. Chem. Soc. 1984, 106, 669-682.

[51] Y. Zhao, D. G. Truhlar, Theor. Chem. Acc. 2008, 120, 215-241.

[52] A. D. Becke, J. Chem. Phys. 1993, 98, 5648-5652.

[53] C. Lee, W. Yang, R. G. Parr, Phys. Rev. B 1988, 37, 785-789.

[54] P. J. Stephens, F. J. Devlin, C. F. Chabalowski, M. J. Frisch, J. Phys. Chem. 1994, 98, $11623-$ 11627.

[55] T. H. Dunning Jr., J. Chem. Phys. 1989, 90, 1007-1023.

[56] S. Grimme, J. Antony, S. Ehrlich, H. Krieg, J. Chem. Phys. 2010, 132, 154104.

[57] A. D. Becke, E. R. Johnson, J. Chem. Phys. 2005, 123, 154101.

[58] E. R. Johnson, A. D. Becke, J. Chem. Phys. 2005, 123, 024101.

[59] E. R. Johnson, A. D. Becke, J. Chem. Phys. 2006, 124, 174104.

[60] A. Karton, J. Comput. Chem. 2016, 38, 370-382.

[61] M. J. Frisch, G. W. Trucks, H. B. Schlegel, G. E. Scuseria, M. A. Robb, J. R. Cheeseman, G. Scalmani, V. Barone, B. Mennucci, G. A. Petersson, H. Nakatsuji, M. Caricato, X. Li, H. P. Hratchian, A. F. Izmaylov, J. Bloino, G. Zheng, J. L. Sonnenberg, M. Hada, M. Ehara, K. Toyota, R. Fukuda, J. Hasegawa, M. Ishida, T. Nakajima, Y. Honda, O. Kitao, H. Nakai, T. Vreven, J. Montgomery, J. A., J. E. Peralta, F. Ogliaro, M. Bearpark, J. J. Heyd, E. Brothers, K. N. Kudin, V. N. Staroverov, R. Kobayashi, J. Normand, K. Raghavachari, A. Rendell, J. C. Burant, S. S. Iyengar, J. Tomasi, M. Cossi, N. Rega, J. M. Millam, M. Klene, J. E. Knox, J. B. Cross, V. Bakken, C. Adamo, J. Jaramillo, R. Gomperts, R. E. Stratmann, O. Yazyev, A. J. Austin, R. Cammi, C. Pomelli, J. W. Ochterski, R. L. Martin, K. Morokuma, V. G. Zakrzewski, G. A. Voth, P. Salvador, J. J. Dannenberg, S. Dapprich, A. D. Daniels, Ö. Farkas, J. B. Foresman, J. V. Ortiz, J. Cioslowski, D. J. Fox, Gaussian 09, rev. E.01, Gaussian, Inc., Wallingford CT, 2009.

[62] J. Poater, I. García-Cruz, F. Illas, M. Solà, Phys. Chem. Chem. Phys. 2004, 6, 314-318.

[63] F. Feixas, E. Matito, J. Poater, M. Solà, J. Comput. Chem. 2008, 29, 1543-1554.

[64] M. Solà, F. Feixas, J. O. C. Jiménez-Halla, E. Matito, J. Poater, Symmetry 2010, 2, 1156-1179.

[65] T. M. Krygowski, M. K. Cyrański, Chem. Rev. 2001, 101, 1385-1420.

[66] T. M. Krygowski, H. Szatylowicz, O. A. Stasyuk, J. Dominikowska, M. Palusiak, Chem. Rev. 2014, 114, 6383-6422.

[67] J. Kruszewski, T. M. Krygowski, Tetrahedron Lett. 1972, 13, 3839-3842.

[68] T. M. Krygowski, J. Chem. Inf. Comp. Sci. 1993, 33, 70-78.

[69] F. Feixas, E. Matito, J. Poater, M. Solà, Chem. Soc. Rev. 2015, 44, 6434-6451.

[70] J. Poater, M. Duran, M. Solà, B. Silvi, Chem. Rev. 2005, 105, 3911-3947.

[71] J. Poater, X. Fradera, M. Duran, M. Solà, Chem. Eur. J. 2003, 9, 400-406.

[72] E. Matito, M. Duran, M. Solà, J. Chem. Phys. 2005, 122, 014109. 
[73] M. Giambiagi, M. S. de Giambiagi, C. D. dos Santos Silva, A. P. de Figueiredo, Phys. Chem. Chem. Phys. 2000, 2, 3381-3392.

[74] R. H. Mitchell, Chem. Rev. 2001, 101, 1301-1315.

[75] J. A. N. F. Gomes, R. B. Mallion, Chem. Rev. 2001, 101, 1349-1383.

[76] D. Geuenich, K. Hess, F. Köhler, R. Herges, Chem. Rev. 2005, 105, 3758-3772.

[77] R. Gershoni-Poranne, A. Stanger, Chem. Soc. Rev. 2015, 44, 6597-6615.

[78] P. v. R. Schleyer, C. Maerker, A. Dransfeld, H. Jiao, N. J. R. van Eikema Hommes, J. Am. Chem. Soc. 1996, 118, 6317-6318.

[79] Z. Chen, C. S. Wannere, C. Corminboeuf, R. Puchta, P. v. R. Schleyer, Chem. Rev. 2005, 105, 3842-3888.

[80] K. Wolinski, J. F. Hilton, P. Pulay, J. Am. Chem. Soc. 1990, 112, 8251-8260.

[81] R. Gershoni-Poranne, A. Stanger, Chem. Eur. J. 2014, 20, 5673-5688.

[82] E. Matito, ESI-3D: Electron Sharing Indexes Program for 3D Molecular Space Partitioning. http://iqc.udg.es/ eduard/ESI, Institute of Computational Chemistry and Catalysis, Girona, 2006.

[83] A. Keith, AIMall (v. 14.11.23), TK Gristmill Software (aim.tkgristmill.com), Overland Park KS, USA, 2014.

[84] R. F. W. Bader, Atoms in Molecules: A Quantum Theory, Clarendon, Oxford, 1990.

[85] R. F. W. Bader, Chem. Rev. 1991, 91, 893-928.

[86] $R M S D=\sqrt{\frac{1}{n} \sum_{i=1}^{n}\left(R_{i}-R_{\text {exp }}\right)^{2}}$ where $R_{i}$ is the running bond length and $R_{\exp }$ is the corresponding experimental value. For the RMSD calculation, we have included all bond lengths shown in Scheme 3.

[87] M. I. Kay, Y. Okaya, D. E. Cox, Acta Crystallogr. Sect. B 1971, 27, 26-33.

[88] T. M. Krygowski, M. Cyrański, A. Ciesielski, B. Świrska, P. Leszczyński, J. Chem. Inf. Comput. Sci. 1996, 36, 1135-1141.

[89] P. Lazzeretti, Prog. Nucl. Magn. Res. Spectr. 2000, 36, 1-88.

[90] P. Lazzeretti, Phys. Chem. Chem. Phys. 2004, 6, 217-223.

[91] J. Poater, M. Solà, R. G. Viglione, R. Zanasi, J. Org. Chem. 2004, 69, 7537-7542.

[92] S. Osuna, J. Poater, J. M. Bofill, P. Alemany, M. Solà, Chem. Phys. Lett. 2006, 428, 191-195.

[93] J. I. Wu, I. Fernández, P. v. R. Schleyer, J. Am. Chem. Soc. 2013, 135, 315-321.

[94] J. M. Schulman, R. L. Disch, J. Phys. Chem. A 1997, 101, 9176-9179.

[95] G. Berionni, J. I. C. Wu, P. v. R. Schleyer, Org. Lett. 2014, 16, 6116-6119.

[96] E. Matito, F. Feixas, M. Solà, J. Mol. Struct. (Theochem) 2007, 811, 3-11.

[97] C. H. Suresh, S. R. Gadre, J. Org. Chem. 1999, 64, 2505-2512.

[98] K. P. Vijayalakshmi, C. H. Suresh, New J. Chem. 2010, 34, 2132-2138.

[99] K. Walzer, M. Sternberg, M. Hietschold, Surf. Sci. 1998, 415, 376-384.

[100] Y. J. Dappe, M. Andersen, R. Balog, L. Hornekær, X. Bouju, Phys. Rev. B 2015, 91, 045427.

[101] J.-i. Aihara, Chem. Phys. Lett. 2002, 365, 34-39.

[102] S. Fias, P. W. Fowler, J. L. Delgado, U. Hahn, P. Bultinck, Chem. Eur. J. 2008, 14, 30933099. 
Scheme 1. (a) The two out of 20 covalent resonant structures of coronene having three $\pi$-sextets (b) The two different representations of coronene molecule according to the Clar (I) and AdNDP (II) models.

(a)

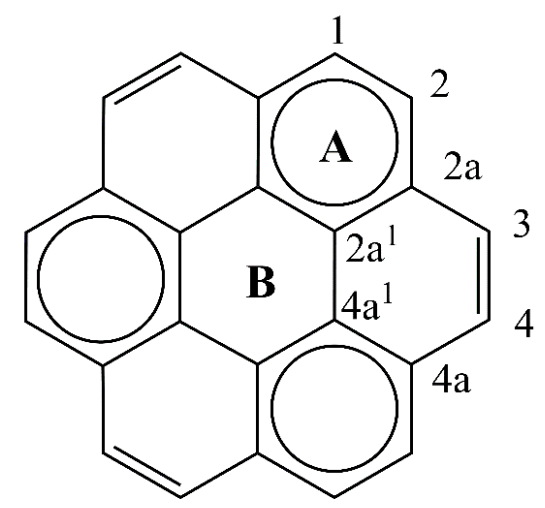

1

(b)

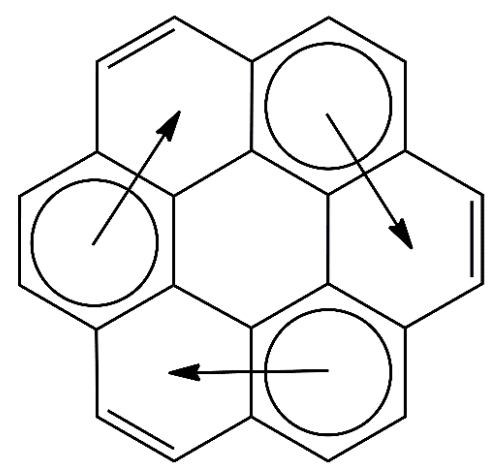

I

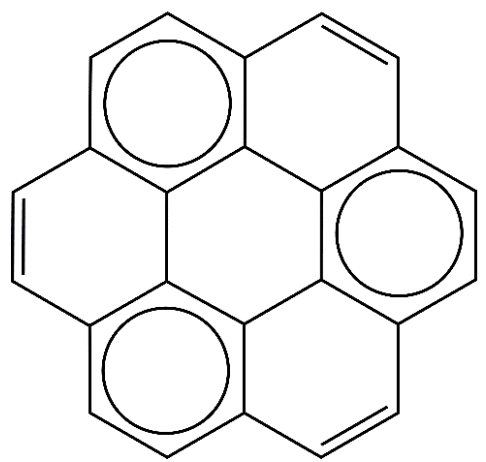

2

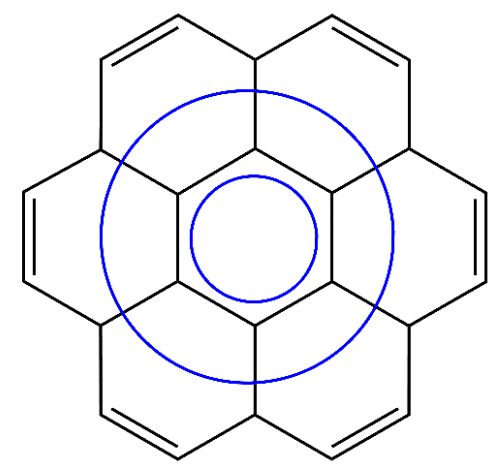

II 
Scheme 2. (a) The Clar representation of naphthalene, (b) the AdNDP model of naphthalene, (c) the representation of phenanthrene according to AdNDP and Clar models, and (d) the Clar representation of pyrene.

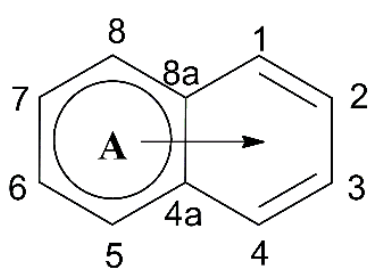

(a)

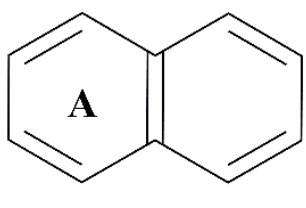

(b)

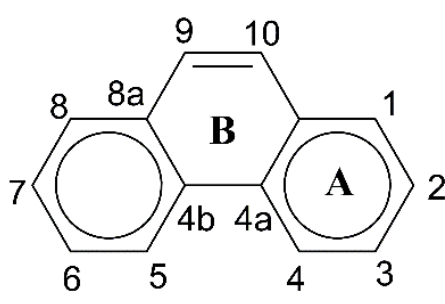

(c)

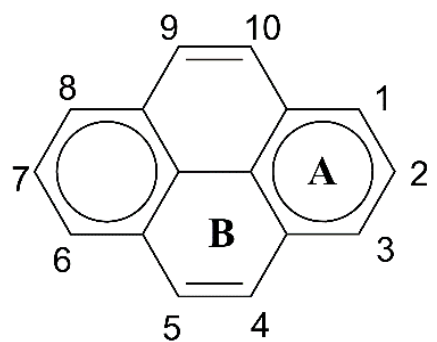

(d) 
Scheme 3. B3LYP/cc-pVTZ, M06-2X/cc-pVTZ (in italics), and experimental (in parentheses) bond lengths (in $\AA$ ) of (a) naphthalene (experimental values from ref. 84), (b) phenanthrene (experimental values from ref. 80), (c) pyrene (experimental values from ref. 97), and (d) coronene (experimental values averaged considering $\mathrm{D}_{6 \mathrm{~h}}$ symmetry from ref. 83).

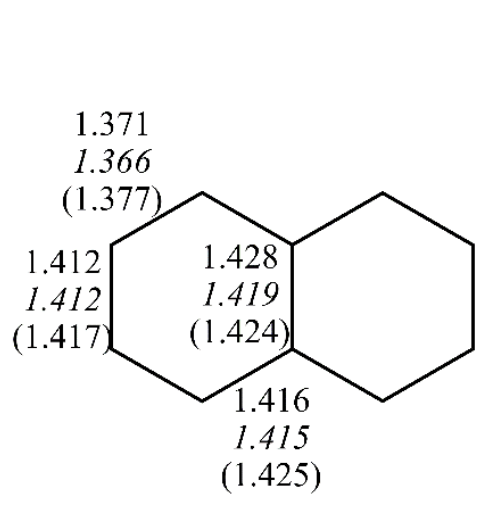

(a)

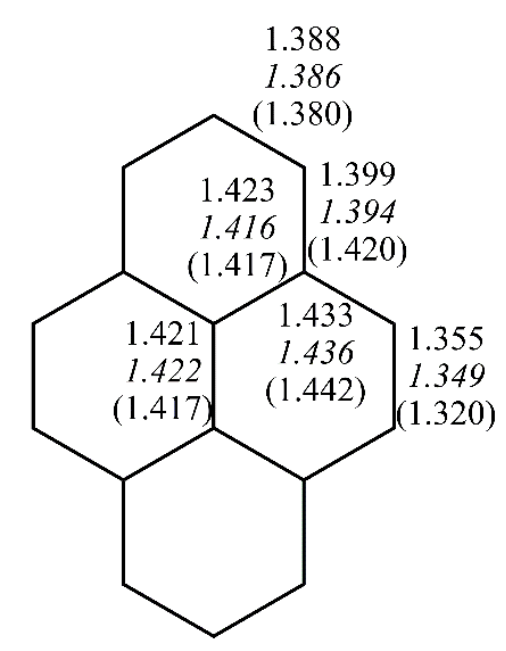

(c)

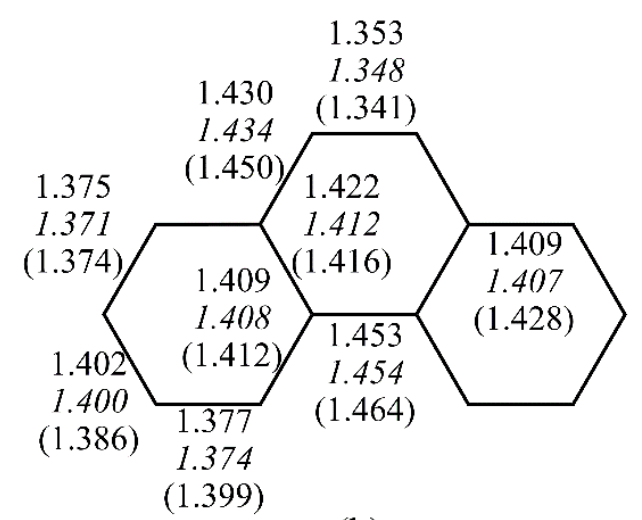

(b)

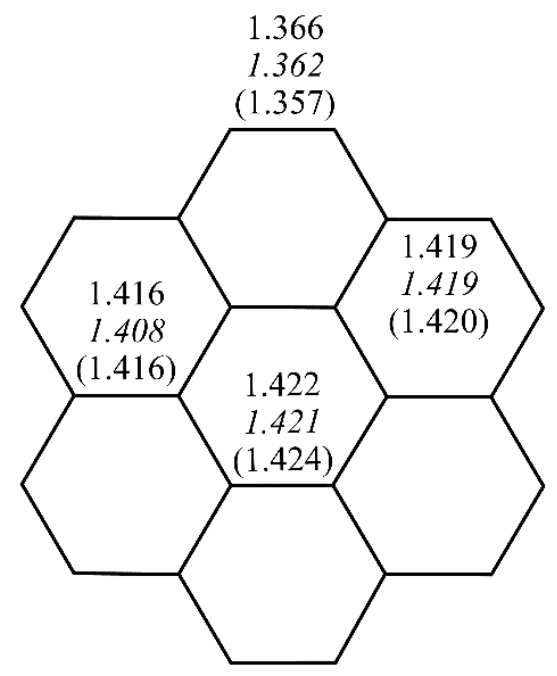

(d) 
Figure 1. M06-2X/cc-pVTZ NICS-X-scan of coronene performed at a height of $1.7 \AA$. The scheme of the considered axis is shown next to the NICS plot.

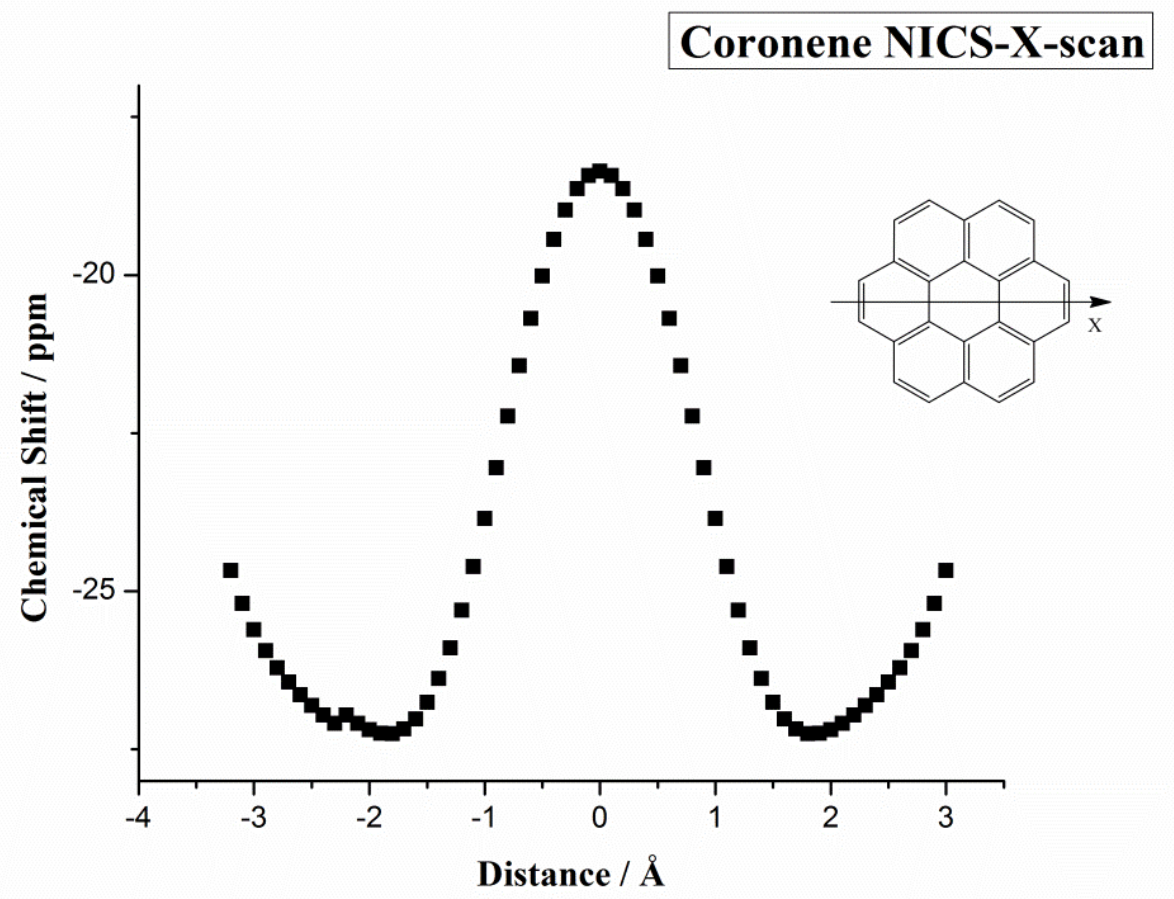


Table 1. M06-2X/cc-pVTZ values of PDI, MCI, and Iring (in electrons), FLU, HOMA, and NICS (in ppm) for the investigated PAHs (see Schemes 1 and 2 for ring labels).

\begin{tabular}{ccccc}
\hline \hline Indices & Ring & Naphthalene & Phenanthrene & Coronene \\
\hline PDI & A & 0.076 & 0.083 & 0.055 \\
\hline FLU & B & & 0.047 & 0.030 \\
\hline MCI & A & 0.010 & 0.005 & 0.013 \\
\hline B & A & 0.038 & 0.047 & 0.020 \\
\hline Iring & B & & 0.017 & 0.024 \\
\hline A & 0.027 & 0.033 & 0.011 \\
\hline BOMA & B & & 0.013 & 0.018 \\
\hline NICS $(1)_{\mathrm{zz}}$ & A & 0.830 & 0.917 & 0.808 \\
\hline & B & -30.42 & -30.50 & -32.42 \\
\hline
\end{tabular}


Table 2. M06-2X/cc-pVTZ values of reaction energies and energy barriers for the investigated PAHs. Enthalpies and Gibbs energies in $\mathrm{kcal} \mathrm{mol}^{-1}$.

\begin{tabular}{c|ccccc}
\hline \hline Compound & Bonds $^{\mathbf{a}}$ & $\mathbf{\Delta} \mathbf{H}_{\mathbf{r}}$ & $\boldsymbol{\Delta G} \mathbf{r}$ & $\mathbf{\Delta \mathbf { H } ^ { \ddagger }}$ & $\boldsymbol{\Delta} \mathbf{G}^{\ddagger}$ \\
\hline Naphthalene & $\mathrm{C} 1-\mathrm{C} 2$ & 1.00 & 14.57 & 30.62 & 35.65 \\
\hline Phenanthrene & $\mathrm{C} 9-\mathrm{C} 10$ & -3.78 & 10.15 & 27.93 & 32.32 \\
\hline Coronene & $\mathrm{C} 3-\mathrm{C} 4$ & 0.35 & 13.29 & 30.53 & 35.02 \\
\hline \hline
\end{tabular}

${ }^{\mathrm{a}}$ Labels of $\mathrm{C}$ atoms in Schemes 1 and 2. 

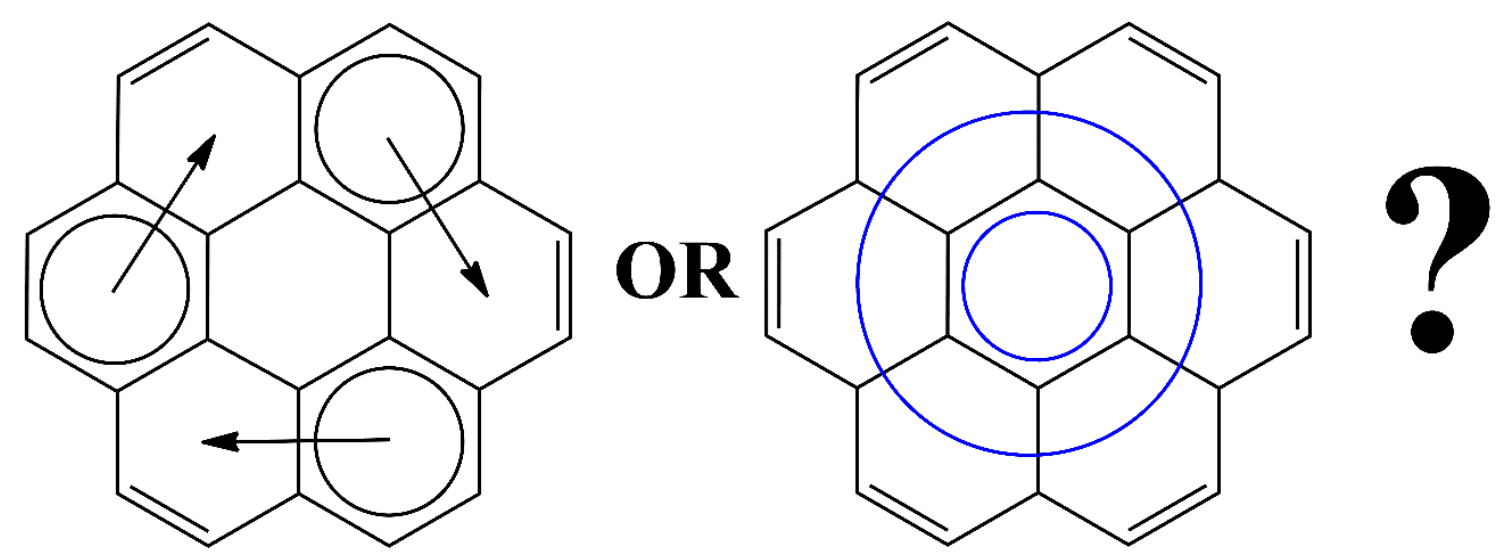

The nature of the chemical bonding in coronene is controversial. Comparison of Clar's aromatic $\pi$ sextet and Adaptative Natural Density Partitioning (AdNDP) models reveals that Clar's $\pi$-sextet model provides the representation that better describes the physicochemical behaviour of coronene. 